\title{
La violence dans l'œuvre de Samuel Beckett, Llewellyn Brown (dir.)
}

Stefano Genetti

\section{(2) OpenEdition}

Journals

\section{Edizione digitale}

URL: http://journals.openedition.org/studifrancesi/10594

DOI: 10.4000/studifrancesi.10594

ISSN: 2421-5856

\section{Editore}

Rosenberg \& Sellier

\section{Edizione cartacea}

Data di pubblicazione: 1 décembre 2017

Paginazione: 582-583

ISSN: 0039-2944

\section{Notizia bibliografica digitale}

Stefano Genetti, «La violence dans l'œuvre de Samuel Beckett, Llewellyn Brown (dir.)», Studi Francesi [Online], 183 (LXI | III) | 2017, online dal 01 février 2018, consultato il 22 janvier 2021. URL: http:// journals.openedition.org/studifrancesi/10594 ; DOI: https://doi.org/10.4000/studifrancesi.10594

Questo documento è stato generato automaticamente il 22 janvier 2021.

\section{(c) (i) $\odot$}

Studi Francesi è distribuita con Licenza Creative Commons Attribuzione - Non commerciale - Non opere derivate 4.0 Internazionale. 


\title{
La violence dans l'œuvre de Samuel Beckett, Llewellyn Brown (dir.)
}

\author{
Stefano Genetti
}

\section{NOTIZIA}

La violence dans l'œuvre de Samuel Beckett, sous la direction de Llewellyn BRown, Paris, Classiques Garnier, 2017, 462 pp.

1 Dedicata alla memoria di Michel, Hélène e Danièle Minard, primi editori della série beckettiana ora pubblicata da Classiques Garnier, questa raccolta di studi verte sulla violenza tanto fisica-colpi inferti e subiti, minacce e supplizi-quanto insita nel linguaggio: le reazioni che suscita la voce incessante del Super-io. È quanto sottolinea il direttore della collana (L. BRown, Samuel Beckett et la violence. Un parcours de l'ouvre, pp. 21-45) in base a un approccio psicanalitico che contraddistingue anche altri contributi come quello, di impostazione lacaniana, sulla musicalità della lingua (Bruno GENESTE, Samuel Beckett, l'"entre" vivifiant de "lalangue" et l'hiatus sinthomatique. Contrer ces vérités du Surmoi, pp. 89-116). Dai parossismi parodici della violenza esercitata sull'altro alla tortura che il prendere la parola implica e alla struttura inquisitoria di certi microdrammi, un'evoluzione si delinea nell'opera verso forme di violenza interne al linguaggio verbale e/o visivo.

2 Sui concetti di interdiscorsività (Bachtin), di «voix soufflée» (Derrida) e di produzione discorsiva controllata dal déjà dit (Foucault) poggia la riflessione di Stéphane BIKIALO sul tormento dettato da una parola allo stesso tempo obbligata e irriconoscibile (Violence $d u$ discours chez Beckett. Les voix de "derrière", pp.49-68): l'accettazione del dialogismo consente tuttavia l'emergere della singolarità. Deleuze e Barthes accompagnano invece la lettura proposta da Cécile YAPAUdjIAN-LABAT di "Worstward Ho" de Samuel Beckett. La violence du "logos" (pp. 69-87): in Cap au pire, il fraseggio di una langue minorée lascia trapelare la resistenza che gli affetti e la soggettività oppongono al movimento di riduzione progressiva verso il nulla che regola il linguaggio del raziocinio. 
3 A partire dall'aggressività verbale con la quale Beckett insiste, nei suoi scritti di critica d'arte, sul conflitto tra il dire e il vedere, Anne-Cécile GuILBARD mostra come esso presieda, assai più tardi, all'uso della telecamera nei drammi per la televisione (Beckett et la violence du voir. «Voir à mort», pp. 283-296). Dallo sguardo luminoso del proiettore che bracca i personaggi ed estorce loro la parola in Comédie, accostato al panopticon di Jeremy Bentham ripreso da Foucault in Surveiller et punir, muove l'argomentazione di Eri MIYAWAKI, arricchita dall'analisi delle versioni manoscritte di un abbozzo in prosa inedito, The long observation of the ray, dove il raggio di luce proveniente da una lanterna che illumina uno spazio dapprima cubico, poi sferico, emblematizza l'occhio della mente che cerca di captarsi, di pensarsi. Connessa all'equivalenza ontologica tra essere ed essere percepito che Beckett mutua da Berkeley, l'asimmetria tra visto e vedente quest'ultimo spesso relegato nell'invisibile - traduce una critica della centralità della visione oculare che caratterizza la filosofia occidentale (Une violence invisible du regard chez Beckett. La rupture entre le voyant et le vu dans l'œuvre ultérieure, pp. 297-309).

Affrontato nell'analisi comparativa di Claire LozIER attraverso la lettura che Bataille ne ha dato in "Critique» nel 1951 (Violence du Beckett de Bataille. "Le silence de Molloy", pp.151-172), il romanzo Molloy è anche l'oggetto di studio scelto dal curatore. Di impulso omicida in proiezione allucinatoria, la violenza si esplica attraverso il motivo del doppio. Alla fine, il personaggio di Moran, nel cui nome è inscritto il genere stesso del roman, incarna la rinuncia a un'identificazione impossibile (L. BRown, Doubles imaginaires et violence dans "Molloy" de Samuel Beckett, pp.129-150). Sulle dinamiche di coppia solitudine/persecuzione, malinconia/mortificazione, abiezione/comunicazione, sull'inversione dei ruoli di vittima e carnefice e sulla violenza come modalità pedagogica disumanizzante si concentra Natália LARANJINHA in merito a Comment c'est, di gran lunga il testo più commentato in questo volume (Samuel Beckett et les meurtrissures du corps, pp. 173-185).

5 L'animalizzato strisciare nel fango delle figure che popolano l'universo crudele di Comment c'est, la nominazione violenta dell'altro e la meccanica delle sevizie che ne costituisce il dressage strutturano l'analisi di Michel BERTRAND, Violence de l'horizontalité chez Samuel Beckett. La boue, les coups et plus si affinités (pp. 187-205), dove alle citazioni «inter-dites» (p. 199) della Commedia dantesca si affianca il rimando a Primo Levi. Derisione del razionalismo, spettacolarizzazione dei rapporti di dominazione e di sottomissione, serialità e ciclicità sono tra i temi affrontati da Anthony CORDINGLEY, che ricorre tra l'altro alla nozione di masochismo contrattuale ("Comment c'est" de Beckett: le ventriloque à la fourrure, pp. 207-226).

Da punti di vista diversi, in molti rinviano al modello sadiano, sul cui influsso, a livello compositivo, stilistico e di imagerie, si sofferma Elsa BAROGHEL contestualizzandolo nell'ambito della ricezione novecentesca dell'opera del Marchese (Samuel Beckett, lecteur de Sade. "Comment c'est" et "Les Cent Vingt Journées de Sodome", pp. 227-259). Fin dal 1938, Beckett dichiara di provare dinanzi ai libertini di Sade un"'estasi metafisica" e, tra il 1950 e il 1951, ancora se ne interessa, traducendo in inglese lettere, estratti e brani di critici, tra i quali predilige Blanchot. All'approccio intertestuale si affianca l'attenzione prestata, per citare il titolo dell'articolo di Éric WESSLER (pp. 263-281), alla Violence comme métaphore de l'écriture dans l'œuvre de Beckett e soprattutto alla dimensione metatestuale di Comment c'est: la creazione artistica come sofferenza auto-inflitta (N. Laranjinha); il fango come fondo d'inchiostro, le unghie che incidono parole sui corpi e l'orizzontalità del movimento a immagine della progressione rettilinea della scrittura 
(M. Bertrand); la violenza come allegoria della relazione tra narratore e narrato, tra scrittore e opera, con particolare riguardo all'attività dell'autotraduzione (A. Cordingley).

7 Precedono l'ampia sezione di recensioni, nonché gli indici dei nomi e delle opere di Beckett, due contributi fuori tema. Garin DowD, alle pp. 349-371, commenta il secondo volume della Corrispondenza, relativo al periodo 1941-1956 (della cui versione francese abbiamo brevemente reso conto nel fascicolo 180). Alle pp.313-345 si fornisce la traduzione della Cronologia del viaggio di Beckett in Germania (28 settembre 1936 2 aprile 1937) approntata da Mark Nixon. Vi si trovano precisati i dettaglispostamenti, progetti e letture, incontri con persone e opere d'arte - di un'esperienza formativa che segna durevolmente l'autore e che lo scrittore belga Stéphane LAMBERT ha recentemente rivisitato, tra saggio e racconto, nel suo avvincente Avant Godot (Paris, Arléa, 2016). 